\title{
FACTORS INFLUENCING CONSUMERS' PERCEPTION TOWARDS MOBILE PAYMENT USAGE IN MALAYSIA
}

\author{
Nur Hazwani Mohamad Roseli \\ Faculty of Business and Management \\ Universiti Teknologi MARA, Cawangan Melaka, Malaysia \\ E-mail: nurha5338@uitm.edu.my \\ Nurul Huda Najihah Azhar \\ Faculty of Business and Management \\ Universiti Teknologi MARA, Cawangan Melaka, Malaysia \\ Muna Kameelah Sauid \\ Faculty of Business and Management \\ Universiti Teknologi MARA, Cawangan Melaka, Malaysia \\ Zuhairah Hasan \\ Faculty of Business and Management \\ Universiti Teknologi MARA, Cawangan Melaka, Malaysia \\ Yuhanza Othman \\ Department of Laws \\ Universiti Teknologi MARA, Cawangan Melaka, Malaysia
}

\begin{abstract}
The advancement of smartphone technologies has led to many promising services such as payment through mobile or smartphone itself. In Malaysia, mobile payment usage is still low because consumers prefer to make payment transactions using other devices like laptops, computers, and credit card machines. Even though the adoption is still low but it shows an increasing trend. The purpose of this paper is to find factors influencing consumers' perceptions of mobile payment usage. This study proposes three factors which are ease of use, trust, and security for the measurement. This quantitative study employed convenience sampling as the sampling technique and a total of 259 consumers as the respondents. All three factors were found could influence the consumers' perception of mobile payment usage. Since this study is only limited to only three factors, there should be other factors to be included in future studies such as perceived cost, perceived benefits, cashback, rewards and many more. The conduct of this study will be beneficial to both service providers as well as the businesses using the services for improving their business models and business strategies.
\end{abstract}

Keywords: Mobile Payment, Consumer Perception, Ease of Use, Trust, Security. 


\section{INTRODUCTION}

Mobile payment or m-payment is a technology-based financial innovation known as FinTech (Financial Technology) that allow payment transactions to be done using any mobile devices. The medium is rising rapidly as it could offer many benefits to the customers to conduct eCommerce transactions or in-store purchasing. The Covid-19 pandemic and movement control order restrictions in Malaysia also the reasons why the adoption of digital payments is growing.

Based on the survey conducted by Malaysian Communications and Multimedia Commission (2018), the most preferred device chosen by the customers to buy any goods and services via online is smartphone (78.3\%). Meanwhile, others would prefer to use laptop, notebook and netbook $(29.7 \%)$, desktop or personal computer $(27.1 \%)$, tablet $(6.2 \%)$ and smart television $(1.1 \%)$. The most common payment method is online banking $(62.1 \%)$, followed by credit card (32.7\%), and debit card (28.5\%). In addition to the payment method mentioned, 8.2 percent of online shoppers use third-party online payments to complete their purchases like PayPal (60.4\%), AliPay (16.3\%), MOLPay (15.8\%) and IPay88 (13.4\%). According to the Mastercard Impact Study 2020 highlighted in Tan (2020), Malaysia leads other Southeast Asian countries in regards of smartphone or digital wallet use. Malaysia has a mobile wallet usage rate of $40 \%$, which places it ahead of other nations such as the Philippines (36\%), Thailand (27\%), and Singapore $(26 \%)$.

The trend is continuously increasing over time as customers believe that mobile payment facilitates secure electronic commercial transactions between merchants and customers. Research that has been done by Yeow Pooi Mun et al. (2017) mobile payments can be categorized into two types namely contactless and remote depends on the type of technology being used. Contactless mobile payments require customers to present physically at the Point of Sale (POS). Furthermore, Near Field Communication (NFC) also falls under this category whereby an NFC-enabled device is installed with payment application and personalized with a payment account such as credit, debit and prepaid cards provided by the financial institutions. In contrast, remote mobile payment does not require customers to interact with the POS directly. The transactions performed rely on the technology like Short Message Service (SMS), secure mobile browser and mobile application. Moreover, examples of mobile payment applications that use QR Code and In-app payments as a payment method are Boost and GrabPay, QR Code and Visa-back Prepaid Card (AEON Wallet), QR Code, NFC and Prepaid Card (BigPay), QR Code (Touch n Go e-Wallet, WeChat Pay, AliPay), Online (Lazada Wallet, PayPal), Magnetic Field Transfer and NFC (Samsung Pay), Global Positioning System (GPS) Location Tracking (Setel), and Barcode (myNEWS Malaysia) (Farhan Gazi, n.d.).

In a mobile payment technology, trust is one of the stronger determinants in continuation of the technology (Maureen Nelloh et al., 2019). The mobile payment providers need to ensure that the platforms offered are safe in order to gain trust from the customers. When the customers believe that their mobile payment account is secured from any intruders, they will put trust on it and use it for a long term. Therefore, trust and security are two main factors that are related with one another.

Even though mobile payment enables customer in purchasing any goods or services yet there are some barriers that need to address. Studies that have been done by Eriksson et al. (2021) the barrier to the usage of mobile payment are the payment procedures are complex, privacy issues, and lack of merchant acceptance, perceived usefulness and customer knowledge. Moreover, security issues regarding the probability of the hackers attack, monetary loss, theft or 
unprotected use (Eriksson et al., 2021) violating privacy and virus attacks are also major concerns (Maureen Nelloh et al., 2019).

This study is solely on the monetary transactions via mobile devices, not limited to any different types of payment method that could offer by the mobile payment providers such as financial institutions or third-party providers. In this study, the authors attempt to investigate the factors that could influence the customers' perception on adoption of the mobile payment usage. Prior studies have recognized that ease of use, trust and security are the common factors that could lead to the determinants of the adoption of mobile payment usage. On the one hand, the study contributes as a reference for the mobile payment providers to have insightful understanding regarding the factors that could influenced the mobile payment usage among customers in Malaysia.

This paper is structured as follows. The next section discusses the literatures on mobile payment, ease of use, trust and security. Section 3 describes the research methodology, followed by the discussion on analysis and findings in Section 4. Finally, the conclusion is drawn, along with some recommendations for future study.

\section{Mobile Payment}

\section{LITERATURE REVIEW}

Mobile-payment can be defined as any financial transaction made from or through a mobile device. Mobile payment is associated with the use of mobile phone specifically smartphones which is one of the greatest innovations that has significant impact to the society and the economy (Liebana-Cabanillas, Sanchez-Fernande, and Munoz-Leiva, 2014). When using mobile payment, one does not require to boot up and shut down a personal computer to make payment. Therefore, the process is much faster and simpler compared to its rivals as users can make payments anytime and anywhere as the mobile terminals can be set to always-on.

Mobile payment is classified into two types; remote payment and proximity payment (Smart Card Alliance, 2011). Remote payment allows user to make payment remotely through mobile communication networks. Variety of mobile phone data channels can be used in remote mobile payment to perform a transaction. The example of this payment includes mobile banking, mobile shopping and peer to peer payments. For these methods of payment, users account is not stored in the user's interface (Shin, Lee and Odom, 2014).

Through proximity payment, users will make payment using a mobile device and shortrange communication technologies (Wang, et. al 2012). One of the examples in proximity payment method is Point-of-sale. In this method, the user's device stored the users' account information in order to perform a prompt transaction by either scanning a barcode/QR code or by using a NFC chip inside the smartphone (Shin, Lee and Odom, 2014).

\section{Ease of Use}

What makes people tend to use a new technology is usually related to whether it is easy to use. Ease of use refers to the perception of an individuals that using a particular system will be easy to handle, simple and effortless (Taylor and Todd, 1995). This factor is very significant in which will affect the customers' intention to use m-payment. Although mobile payment brings a lot of benefits to both users and the merchant, some individuals might find it difficult to master (Davis, 1989). To people who are not that familiar with information technology, the design of a system should be fully adaptable to their capabilities and skills (Kourouthanasis, Giaglis and Karaikos, 2010). Numerous studies revealed ease of use to be one of the most critical factors to have a 
direct impact on an individual behavioural intention to adopt mobile payment services (Chen, 2008, Kim, et. al, 2010). A study conducted by Chen (2008) found that consumers are more likely to adopt mobile payment if it is easy to use. This signifies that, the design of the mobile payment devices must be easily understood so that the payment procedure can be perform without any hassle. The following hypothesis is suggested;

\section{H1. Ease of use has positive influence on mobile payment usage}

\section{Trust}

In an online environment, McKnight (2002) conceptualize trust as the belief of consumers to willingly taking risk for an expected service after considering the vendors' characteristics. Trust is associated with positive attitudes that likely to encourage the consumer's intention to adopt the technology (Gefen, 1997; Jarveenpaa and Tractinsky, 1999). In a study conducted by Siau and Shen (2003), trust can be divided into two categories. Firstly, the trust in the ability of mobile technology to minimize transaction risks. Since mobile technology is still relatively new, customers may have doubts with its technology and its operational environment (Chandra et. al. 2010; Eze et. al 2008). Secondly whether the service providers will meet the expectations of customers. Customers trust over payment provider is greatly influenced by the organization's reputation (Xu and Gutierrez, 2006; Anderson and Weitz, 1989). Results of a study conducted by Hampshire (2017) revealed that customers with high confidence level for the mobile payment services have higher tendency to use the services.

\section{H2. Trust has positive influence on mobile payment usage}

\section{Security}

Security is one of the most important measures when it comes to using mobile payment. Regardless of the cost or convenience of services offered, a payment method must be reliable and secure or else people will refuse to use it (Litan and Baily 2009). In mobile payment environment, security is measured based on whether all the technological steps and procedures involved are satisfied and secured in terms of protecting confidentiality, integrity, availability and accountability (Karnouskos, Hanroudaki, Vilmos and Csik, 2004) of the transaction. Security issues will increase the risk perception among the users and lowers their intention to continue using it (Shao et. al. 2019). A study on consumers' privacy attitudes concerning mobile payments, reveals that American consumers would strongly reject systems that track and share their personal information with the merchant (Hoofnagle, Urban, and Li, 2012).

\section{H3. Security has positive influence on mobile payment usage}

\section{METHODOLOGY}

This study addresses the factors influencing consumers' perception of mobile payment usage. This quantitative study used convenience sampling to obtain information from a particular subset of the population. Due to the pandemic of Covid-19, the location of the respondents was taken into consideration. Therefore, the respondents were selected based on the nearest population to the researchers.

The unit of analysis of the study is an individual and about 371 hard copy of structured questionnaires were distributed randomly to people residing at Bukit Rambai, Melaka. This study 
adopts the sample size by Krejcie and Morgan thus, 259 copies of the completed questionnaire were returned.

Before the actual study was conducted, the study was piloted among 30 respondents. The results from pilot tests have been evaluated and those have been considered to the actual tests. The survey instrument consisted of 3 sections. Section A is about the demographic question, Section B is on consumer's perception of mobile payment usage and Section $\mathrm{C}$ is about the factors that affect consumer's perception of mobile payment usages.

\section{Demographic Analysis}

\section{DISCUSSION ON ANALYSIS AND FINDINGS}

The demographic distribution of the sample was $59.5 \%$ male and $40.5 \%$ female; $82.2 \%$ Malay, $13.1 \%$ Chinese and $4.6 \%$ Indian; all of the respondents were in the age between 15 to 59 where the highest percentage, $56.8 \%$ at the range of 20-29 years old and the lowest percentage, $0.8 \%$ at the range of 50-59 years old. Data on education level indicated that $40.2 \%$ were from Diploma, 29.7\% Degree, 20.5\% SPM, 9.3\% other education level and 0.4\% Master holder. Most of the respondents came from non-government sector $(54.8 \%)$, followed by government sector (26.3\%), non-working (9.7\%) and self-employed (9.3\%). The highest respondents' rate with the highest interest on mobile payment were those with salary of RM1000-RM2000 (61\%) and respondents that have salary less than RM1000 (0.4\%) showed less interest in mobile payments. Mobile banking apps showed the highest preference (34.3\%), followed by Applypay (25.1\%), Paypal (21.2\%) and Mobilepay (19.7). Majority of the respondents had experienced using mobile payment at the range of 1 to 2 years (54.1\%), 7 to 12 months $(24.7 \%), 3$ to 6 months $(12 \%)$, more than 2 years $(8.9 \%)$ and less than 3 months $(0.4 \%)$.

\section{Correlation Analysis}

Correlation analysis was conducted among the three factors related to consumer perception towards mobile payment. The results show that three factors, trust, ease of use and security are significantly linked to the perception of consumers as dependent variables towards mobile payment. Correlation is a quantitative technique that can reveal if and how strongly pairs of variables are associated with each other. The variables were said to be correlated if one variable's movement is accompanied by another variable's movement. Analysis of correlation measures the relationship between two dependent and independent variables. The goal is to see if a change in the independent variables will result in the dependent variable being changed. If the data is normal, Pearson Correlation is the technique used.

The results illustrated in Table 1 show that all the correlations were statistically significant $(\mathrm{p}<0.01)$. These findings show that the correlation coefficients were positive, indicating that relationship between trust and consumer perception towards mobile payments is significant. Trust is positively associated with consumer perception $(r=.808, p=.000)$. The findings accept the hypothesis and indicate that, if the customers feel trust with the services, they will continue the next process without any doubt with the mobile payment. The finding is consistent with previous related studies in which trust is highly associated with customers' perceptions that are using the mobile payments. Based on Sohrab Khan et al. (2019) trust refers to the concept of a willingness to be vulnerable to other's actions. According to Madureira (2017) trust guarantees reasonable expectations of a secure and consistent mobile payment system and that no harmful effects can occur while using it. 
This study also hypothesized the relationship between ease of use and consumers' perception towards mobile payments. The results showed that the relationship between ease of use and consumer perception towards mobile payments is significant at $(r=.807, p=.000)$. The findings indicate that, if the customer is feeling satisfied and comfortable with the mobile payments' services, the possibility for them to use it again is high and they will repeat to use the mobile payments. Therefore, relationship between ease of use and consumers' perception towards mobile payments is positive and the finding hypothesis is accepted. Ease of use is highly associated with customers' perceptions that are using the mobile payments and it is consistent with the previous related study. Based on Wendy Ming-Yen Teoh et al. (2013) the Cronbach alpha is almost same with this research which is 0.841 while in this research it is only 0.807 . Consequently, the respondents will feel that the instruction given is much simpler and thus less difficult are the steps to execute the transaction.

The third hypothesis is to test whether is any relationship between security and consumers' perception towards mobile payments. The results from this study indicate security in mobile payments has strong relationship with customer perception and significant at $(\mathrm{p}<0.01)$. Therefore, this research will delete the null hypothesis and conclude that there is significant relationship between security and consumers' perception towards mobile payment. The findings of Lim et al. (2007) stated that the adoption of e-payment decisions will be affected by security concerns, and this is also consistent with the results of this research. Three independent variables in this analysis include trust, ease of use, and security to have a positive relationship with consumer perception of mobile payment. All variables are positively related based on the value of the coefficients. Reached the conclusion and discussed that the multiple regression used by Pearson Correlation to find out the relationship between independent variables and dependent variable.

Table 1. Pearson Correlation Analysis

\begin{tabular}{|c|c|c|c|c|c|}
\hline & & $\begin{array}{l}\text { Consumer } \\
\text { Perception }\end{array}$ & Trust & $\begin{array}{c}\text { Ease of } \\
\text { Use }\end{array}$ & Security \\
\hline \multirow{3}{*}{$\begin{array}{l}\text { Consumer } \\
\text { perception }\end{array}$} & Pearson Correlation & 1 & & & \\
\hline & Sig. (2-tailed) & & & & \\
\hline & $\mathrm{N}$ & 259 & & & \\
\hline \multirow[t]{3}{*}{ Trust } & Pearson Correlation & $.808^{* *}$ & 1 & & \\
\hline & Sig. (2-tailed) & .000 & & & \\
\hline & $\mathrm{N}$ & 259 & 259 & & \\
\hline \multirow[t]{3}{*}{ Ease of use } & Pearson Correlation & $.807^{* *}$ & & 1 & \\
\hline & Sig. (2-tailed) & .000 & & & \\
\hline & $\mathrm{N}$ & 259 & & 259 & \\
\hline \multirow[t]{3}{*}{ Security } & Pearson Correlation & $.690^{* *}$ & & & 1 \\
\hline & Sig. (2-tailed) & .000 & & & \\
\hline & $\mathrm{N}$ & 259 & & & 259 \\
\hline
\end{tabular}




\section{CONCLUSION AND RECOMMENDATION}

The purpose of this research is to explore the relationship between trust, ease of use, security and perception of consumers towards mobile payment. Researchers found, based on the results that goals were achieved, and all the hypotheses accepted. A total of 259 questionnaires have been given to respondents that questioning about the gender, age, education, race, employment status, salary, marital status, types of used payment and how long they have been using the mobile payment. The most respondent are Male. Most respondents are between the ages of 20 and 29. Level of education that is using the most of mobile payment is from Diploma Holder. Malay are the most frequent user of mobile payment and non-government people are the highest respondents using mobile payment. Most of the respondents spending 1000-2000 Ringgit Malaysia and they are being using this mobile payment for 1-2 years by using mobile banking applications.

Based on this research the users should also be careful as there are several risks they will anticipate. A more organized setup is necessary if it comes to the mobile payment concept. Therefore, they need to control measures such as always update and upgrade the security system when it comes to make transaction of payment, especially the security aspects need to be considered to improve the scope of Internet-based business. This is important to gain people's trust in the mobile payment. Thus, the authorities and governments should regulate their use Internet is a business, so that it is not abused by irresponsible people.

Results of this study provide important implications for the telecommunications service providers and owners regarding marketing strategies. The telco service providers should focus on attention to upgrading the services and facilitate their service with advance features. The results from this research provide a platform for Malaysia to understand consumer behavior and how it affects their purchase decision. It is important to note that despite the fact that the respondents were asked about these three factors, there are other factors that shall be included for future study that will help to increase the numbers of users in mobile payment such as perceived cost, perceived benefits, cashback and rewards. In order to ensure that the findings of sample are representative, future research could include with larger number of respondents. The current study supports much of the previous study on the customer behavior and finally reinforces the need for revisit the advance features in telecommunication services as the industry emerge.

\section{REFERENCES}

Alliance, S. C. (2011). The mobile payments and NFC landscape: A US perspective. Smart Card Alliance, 1-53.

Anderson, E., \& Weitz, B. (1989). Determinants of continuity in conventional industrial channel dyads. Marketing science, 8(4), 310-323.

Chandra, S., Srivastava, S. C., \& Theng, Y.-L. (2010). Evaluating the role of trust in consumer adoption of mobile payment systems: An empirical analysis. Communications of the Association for Information Systems, 27(561-588).

Chen, L.-d. (2008). A model of consumer acceptance of mobile payment. International Journal of Mobile Communications, 6(1), 32-52.

Davis, F. D. Perceived usefulness, perceived ease of use, and user acceptance of information technology. MIS Quarterly, 13, 3, 1989, 319-340

Eriksson, N., Gökhan, A., \& Stenius, M. (2021). A qualitative study of consumer resistance to mobile payments for in-store purchases. Procedia Computer Science, 181(2019), 634641. https://doi.org/10.1016/j.procs.2021.01.212 
Eze, U. C., Gan, G. G. G., Ademu, J., \& Tella, S. A. (2008). Modelling user trust and mobile payment adoption: a conceptual Framework. Communications of the IBIMA, 3(29), 224231.

Farhan Gazi. (n.d.). What Is An E-Wallet And How Is It Different From A Credit Card? Retrieved April 22, 2021, from https://www.imoney.my/articles/choosing-e-wallet

Gefen, D. (1997). Building users' trust in freeware providers and the effects of this trust on users' perceptions of usefulness, ease of use and intended use of freeware. Georgia State University.

Hampshire, C. (2017). A mixed methods empirical exploration of UK consumer perceptions of trust, risk and usefulness of mobile payments. International Journal of Bank Marketing.

Jarvenpaa, S. L., Tractinsky, N., \& Saarinen, L. (1999). Consumer trust in an Internet store: A cross-cultural validation. Journal of Computer-Mediated Communication, 5(2), JCMC526.

Karnouskos, S., Hondroudaki, A., Vilmos, A., \& Csik, B. (2004, July). Security, trust and privacy in the secure mobile payment service. In 3rd International Conference on Mobile Business (Vol. 35).

Kourouthanassis, P. E., Giaglis, G. M., \& Karaiskos, D. C. (2010). Delineating "pervasiveness" in pervasive information systems: a taxonomical framework and design implications. Journal of Information Technology, 25(3), 273-287. doi:10.1057/jit.2009.6

Liébana-Cabanillas, F., Sánchez-Fernández, J., \& Muñoz-Leiva, F. (2014). Antecedents of the adoption of the new mobile payment systems: The moderating effect of age. Computers in Human Behavior, 35, 464-478.

Lim, B., Lee, H., \& Kurnia, S. (2007). Exploring the reasons for a failure of electronic payment systems: A case study of an Australian company. Journal of Research and Practice in Information Technology, 39(4), 231-243.

Litan, R. E., \& Baily, M. N. (Eds.). (2009). Moving money: the future of consumer payments. Brookings Institution Press.

Madureira, A. (2017). Factors that hinder the success of SIM-based mobile NFC service deployments. Telematics and Informatics, 34(1), 133-150. https://doi.org/10.1016/j.tele.2016.05.003

Malaysian Communications and Multimedia Commission, \& Malaysian Communications \& Media Commision. (2018). E-Commerce Consumers Survey 2018. In Malaysian Communications and Multimedia Commission.

Maureen Nelloh, L. A., Santoso, A. S., \& Slamet, M. W. (2019). Will users keep using mobile payment? It depends on trust and cognitive perspectives. Procedia Computer Science, 161, 1156-1164. https://doi.org/10.1016/j.procs.2019.11.228

McKnight, D.H., V. Choudhury, and C. Kacmar (2002) "Developing and Validating Trust Measures for E-Commerce: An Integrative Typology", Information Systems Research (13)3, pp. 334-359

Shao, Z., Zhang, L., Li, X., \& Guo, Y. (2019). Antecedents of trust and continuance intention in mobile payment platforms: The moderating effect of gender. Electronic Commerce Research and Applications, 33, 100823.

Shin, S., Lee, W. J., \& Odom, D. O. (2014). A Comparative Study Of Smartphone Users Perception And Preference Towards Mobile Payment Methods In The US And Korea. Journal of Applied Business Research (JABR), 30(5), 1365-3176.

Siao, K., \& Shen, Z. (2003). Building customer trust in m-commerce. Communications of the 
ACM, 46(4), 91-94.

Sohrab Khan, Nor Zairah Ab Rahim, \& Nurazean Maarop. (2019). A review on antecedents of citizen's trust in government social media services. 3C Tecnología_Glosas de Innovación Aplicadas a La https://doi.org/10.17993/3ctecno.2019.specialissue.10

Tan, J. (2020). Mastercard: Malaysia Has Highest Mobile Wallet Usage In Southeast Asia. RinggitPlus. https://ringgitplus.com/en/blog/e-wallet/mastercard-malaysia-has-highestmobile-wallet-usage-in-southeast-asia.html

Taylor, S., Todd, P.A., 1995. Understanding information technology usage: a test of competing models. Information Systems Research 6, 144-176.

Urban, J. M., Hoofnagle, C. J., \& Li, S. (2012). Mobile phones and privacy. BCLT Research Paper Series.

Wang, L., \& Yi, Y. (2012). The impact of use context on mobile payment acceptance: An empirical study in China. In Advances in computer science and education (pp. 293-299). Springer, Berlin, Heidelberg.

Wendy Ming-Yen Teoh, Siong Choy Chong, Binshan Lin, \& Jiat Wei Chua. (2013). Factors affecting consumers' perception of electronic payment: An empirical analysis. Internet Research, 23(4), 465-485. https://doi.org/10.1108/IntR-09-2012-0199

$\mathrm{Xu}$, G., \& Gutiérrez, J. A. (2006). An exploratory study of killer applications and critical success factors in M-commerce. Journal of Electronic Commerce in Organizations (JECO), 4(3), 63-79.

Yeow Pooi Mun, Haliyana Khalid, \& Devika Nadarajah. (2017). Millennials' Perception on Mobile Payment Services in Malaysia. Procedia Computer Science, 124, 397-404. https://doi.org/10.1016/j.procs.2017.12.170

\section{Copyrights}

Copyright for this article is retained by the author(s), with first publication rights granted to the journal. This is an open-access article distributed under the terms and conditions of the Creative Commons Attribution license (https://creativecommons.org/licenses/by/4.0) 